\title{
The optimal level of windpower that could be regulated with Norway's existing hydroreservoirs
}

\author{
Eero Hirvijoki ${ }^{a}$ \\ Department of Applied Physics, Aalto University, P.O. Box 11100, 00076 Aalto, Finland
}

Received: 4 February 2020 / Accepted: 6 March 2020

(C) The Author(s) 2021

\begin{abstract}
This study estimates the optimal level of wind-generated electricity production in Nordic countries' market region given the existing hydroreservoirs of Norway to regulate the intermittency in wind-energy production and to meet the market demand. Using realized, scaled patterns for hourly wind production and electricity demand, we perform a series of numerical simulations and find a threshold value of approximately 90 TWh for annual wind production after which surplus and deficit in the production begin to accumulate significantly, weakening the utilization factor of wind installments. In light of the ambitious climate policies in the Nordic countries, and that the existing annual capacity of installed wind in the region is approximately $41 \mathrm{TWh}$, the Nordic governments should consider investing heavily in both national and international grid infrastructure to enable private sector to double the existing wind capacity in the market region.
\end{abstract}

\section{Introduction}

Utilization factor plays a significant role in the assessment of economic feasibility of electricity production methods that are dominated by capital costs. If the unit is not producing electricity, neither is it generating returns on the investment. In large-scale wind-energy production, the utilization factor is affected by at least the natural variation in wind speeds and the electricity demand in the market together with the availability of regulating power to counter the natural variation and to meet the market demand. Optimal sizing of wind and regulating resources minimizes the utilization factor reducing surplus production that leads to curtailment while keeping the deficit, detrimental to the stability of the electricity network, under control.

Excluding biomass for its unrivaled capability to bind carbon to the soil [1] and its possible future role as a valuable source of biofuels for sectors that are difficult to electrify, remaining present-day low-carbon-footprint options for regulating large-scale windpower production are in practice limited to hydropower and nuclear power-both hydro and nuclear offer quick response times [2,3] while scenarios relying heavily on storage technologies are rather hypothetical [4]. With respect to hydroenergy, Scandinavia is privileged: Norway and Sweden cover over $90 \%$ and $40 \%$ of their annual electricity production with hydropower, corresponding roughly to $135 \mathrm{TWh}$ and $65 \mathrm{TWh}$, respectively. More importantly, Norway's

\footnotetext{
a e-mail: eero.hirvijoki@gmail.com (corresponding author)
} 
hydropower reservoirs have a maximum storage capacity of $87 \mathrm{TWh}$ and a peak power production capabilities reaching $33 \mathrm{GW}$, providing valuable buffering capabilities to regulate the intermittency in, e.g., wind-energy production. For Sweden, the storage and peak power capacities are approximately $33 \mathrm{TWh}$ and $16 \mathrm{GW}$, respectively.

In 2018, the annual generation of electricity from wind in the Nordic countries was 6 TWh in Finland, 16 TWh in Sweden, 15 TWh in Denmark and 4 TWh in Norway, accounting to a total of 41 TWh. In light of the ambitious climate policies in the Nordic countries [5], one cannot avoid asking how much more wind-generated electricity would it be sensible to implement in the Nordic countries' electricity market region, counting for the available hydroreservoirs to serve as a regulating factor. The purpose of this research note is to provide a realistic estimate of that number using realized data for the patterns of hourly wind production and electricity demand, given the hydroreservoirs of Norway to regulate the wind supply.

Per our numerical simulations, we find an optimal level of wind to be approximately $90 \mathrm{TWh}$, which is to be complemented with approximately $120 \mathrm{TWh}$ of hydro-generated electricity, meeting a total demand of $210 \mathrm{TWh}$ annually. This corresponds to a $43 \%$ share of wind of the combined production to meet the demand and is in line with previous studies that have focused on investigating intermittent energy source integration into electricity networks [6-8] and cost-effectiveness of such scenarios [9]. Implementing more wind would facilitate meeting a larger market demand but with the downside of facing a rapid increase in surplus and deficit wind production, eventually calling for more regulating resources and reducing the utilization factor of the implemented wind. As the optimal level we find is more than double the currently installed capacity of approximately $41 \mathrm{TWh}$, the Nordic governments should consider investing in international grid infrastructure to encourage private sector investments in wind. After all, the Nordic-area countries-Denmark, Norway, Sweden, Finland, Estonia, Latvia and Lithuania - still produce approximately 44 TWh of electricity annually from fossil sources. Currently the transfer capacities in this region are lacking.

\section{Model description}

To obtain a quantitative estimate of how much windpower Norway's hydroreservoirs could support, we look into the freely available data maintained by the Norwegian Water Resources and Energy Directorate to extract the average status of the reservoirs and to estimate their accumulation rate-see "Appendix A" for a Python code snippet. The 20-year-average values for the low, median and high reservoir status are illustrated in Fig. 1a while the corresponding inferred rate of accumulation, typically resulting from rainfall and snowmelt, is illustrated in Fig. 1b. We have estimated the accumulation rate from the median 20-year-average reservoir status assuming a constant extraction rate of $133 \mathrm{TWh}$ annually, in lack of better data. We also note that Norway has a colorful mix of hydroplants and reservoirs operating in parallel and series, but this study will approximate them as one entity.

Given the replenishing rate of the hydroreservoirs, the next data sets we look for are realistic hourly patterns for wind-electricity production and the market demand. These we choose to obtain from Fingrid-Finland's transmission system operator-using the Python code snippet described in "Appendix B". The patterns, as illustrated in Fig. 2, reflect the high intermittency in wind production throughout the year as well as the seasonal and hourly variation in electricity demand, peaking during the coldest winter months. The specific wind and demand data sets shown correspond to the realized data in Finland during 2018.

${ }_{1}^{1}$ Accessing the Fingrid data requires a free registration to receive a personal API key. 


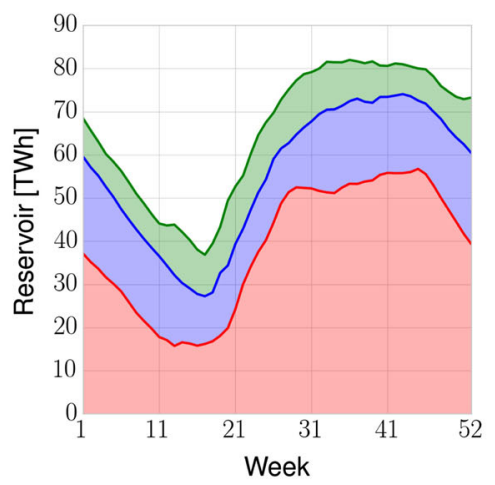

(a) The 20-year-average low (red), median (blue), and high (green) reservoir status throughout the year.

Fig. 1 Integrated hydroreservoirs in Norway

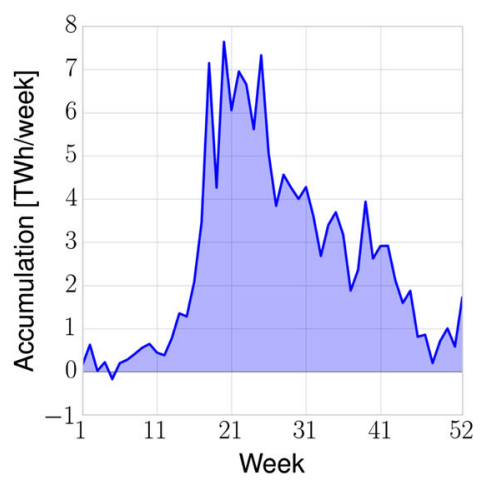

(b) Inferred reserve accumulation computed from the median 20-year-average reserve status assuming a constant demand of $133 \mathrm{TWh}$ annually.

The patterns for wind production and electricity demand will be used as the basis of our modeling by scaling them appropriately: The patterns are held fixed while the accumulated annual production and demand are treated as variables in parameter scans. Our model will consist of the following variables:

- $P_{\mathrm{h}}$ the average hourly power extraction from hydroreservoirs.

- $P_{\mathrm{h}, \max }$ the maximum power output from the hydroreservoirs, $33 \mathrm{GW}$.

- $P_{\mathrm{h}, \text { in }}$ the hourly power input into the hydroreservoir status from the data set in Fig. $1 \mathrm{~b}$.

- $P_{\mathrm{w}}$ the hourly windpower supply based on the pattern in Fig. 2a and scaled appropriately.

- $P_{\text {demand }}$ the hourly market power demand based on the pattern in Fig. $2 \mathrm{~b}$ and scaled appropriately.

- $E_{\mathrm{r}}$ the hourly energy-storage status of the hydroreservoir.

- $E_{\mathrm{r}, \max }$ the maximum energy capacity of the hydroreservoir, $87 \mathrm{TWh}$.

Additionally, the initial value of the hydroreservoir is set to $60 \mathrm{TWh}$ at the beginning of the year, corresponding approximately to the 20 -year-average median value at the beginning of the year.

The method for simulating the one-year surplus and deficit, as well as the reservoir status, is summarized in Algorithm 1. Using the algorithm, the workflow consists of scanning different scalings for the installed wind and checking what level of electricity demand the combined wind and hydro could meet. Additionally, we require that (i) the reservoir status at the end of the year is at least at the same level as in the beginning of the year and that (ii) the hydroreservoir is used at a rate that keeps it from accumulating beyond its maximum capacity. These additional constraints are used as exclusion criteria during the parameter scans and will help in finding the optimal sizing of the wind installment while making sure the existing hydroreservoirs are fully utilized at a level sustainable from year to next.

\section{Results}

We perform a matrix of simulations with the scalings for the annual wind production ranging from 0 to $160 \mathrm{TWh}$ and the annual demand ranging from 100 to $300 \mathrm{TWh}$. The generated 


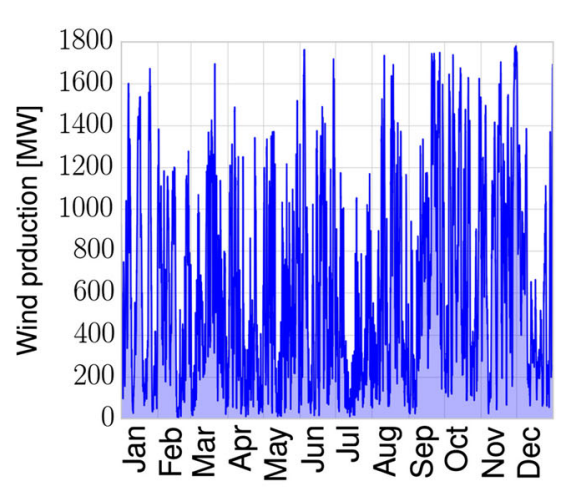

(a) Hourly wind production

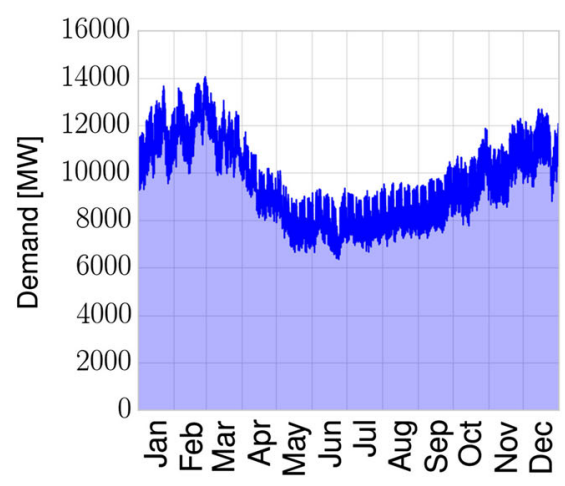

(b) Hourly electricity demand.

Fig. 2 Wind production and electricity demand in Finland in 2018

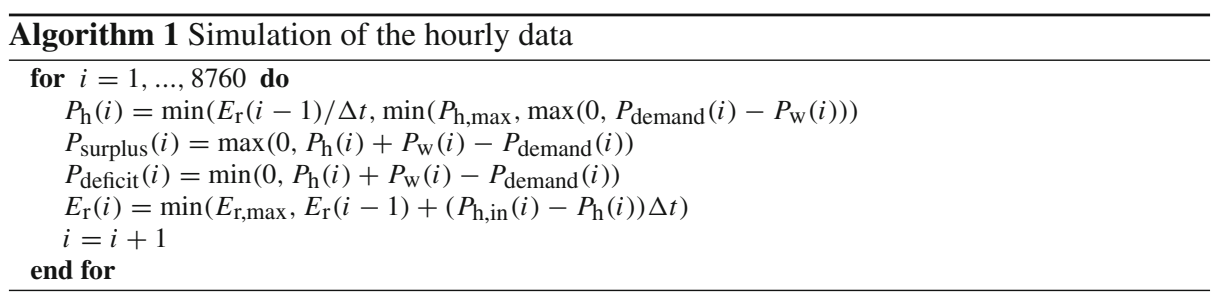

surplus and accumulated deficit are illustrated in Fig. 3 and demonstrated a fairly narrow slice for the optimal range in wind production per given demand. The results also indicate a significant increase in the surplus production once the level of approximately $90 \mathrm{TWh}$ of annual wind production has been reached: 8-9 TWh surplus at 130 TWh production and 15$18 \mathrm{TWh}$ surplus at $160 \mathrm{TWh}$ production. More importantly, the annual deficit - the failure to meet the market demand with a combination of wind and hydro-begins to deviate from zero after the threshold value of $90 \mathrm{TWh}$ is reached and one aims to meet a net demand larger than $210 \mathrm{TWh}$.

After a careful inspection of Fig. 3, one is likely prompted with the question of why not more than 90 TWh annually. After all, a total deficit of 2 TWh appears insignificant when it is compared to annual production of $160 \mathrm{TWh}$ of which $15-18 \mathrm{TWh}$ is lost as surplus, especially if one could meet an annual demand of approximately $280 \mathrm{TWh}$ when combining the wind and hydro resources. A better insight into this question, and to the role of the deficit, is obtained after inspecting the hourly behavior of the wind surplus and deficit. Figure 4 illustrates the balance of surplus and deficit in our proposed optimal scenario with $90 \mathrm{TWh}$ of annual wind-electricity production and in a scenario with approximately $160 \mathrm{TWh}$ of wind production. While the total annual deficit remains low, only at the aforementioned $2 \mathrm{TWh}$, the hourly power deficit peaks at $10 \mathrm{GW}$ and is on average approximately $5 \mathrm{GW}$. This is a combined effect of the seasonal and hourly variations in the electricity demand as well as the high hourly variation in the wind-electricity production. Consequently, to meet the occasional 5-10 GW power deficits, a relatively large base of very likely carbon-based regulating-power reservoir would be necessary. This relatively large power-generation capacity would remain unused throughout most of the year and, from the economic point of view, effectively increase 


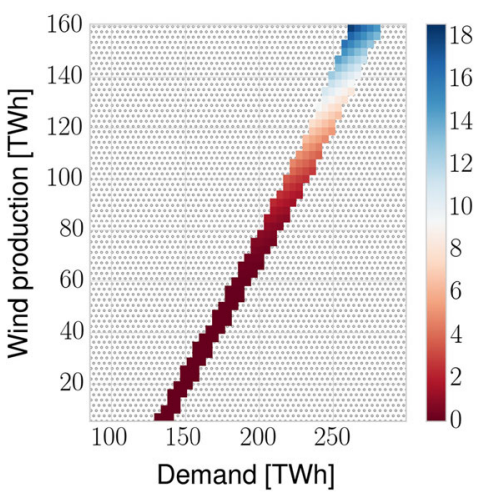

(a) Surplus (color) [TWh]

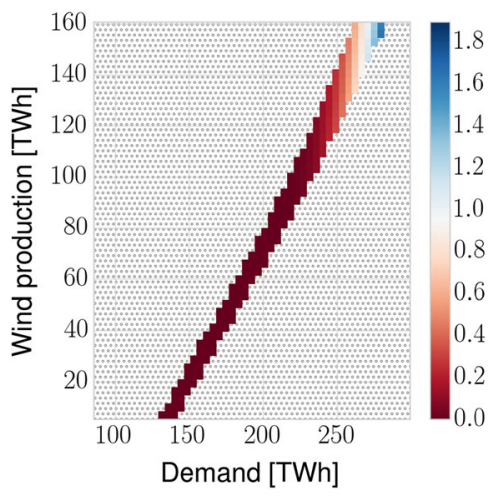

(b) Deficit (color) [TWh]

Fig. 3 Color-coded annual surplus and deficit as a function of annual electricity demand and wind-electricity production. Surplus arises from momentarily production peaks that exceed momentarily demand and deficit from momentarily not meeting the demand. The shaded region refers either to exceeding the hydroreservoir storage capacity (upper left area) or not meeting the requirement of the end-of-the-year reservoir status to be at least at the same level as in the beginning of the year (lower right area)

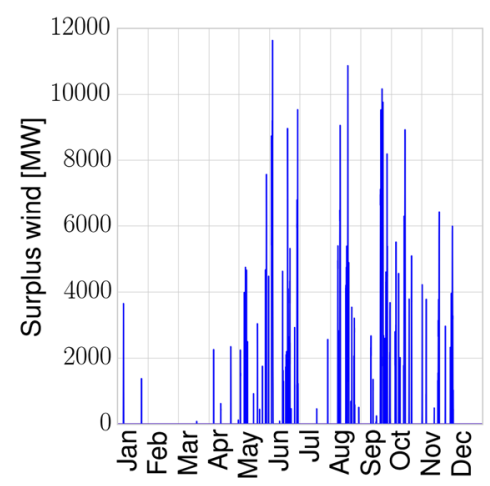

(a) Near optimal: surplus $2.5 \mathrm{TWh}$, deficit $0.0 \mathrm{TWh}$, wind $91 \mathrm{TWh}$, hydro $121 \mathrm{TWh}$, demand 209.5 TWh.

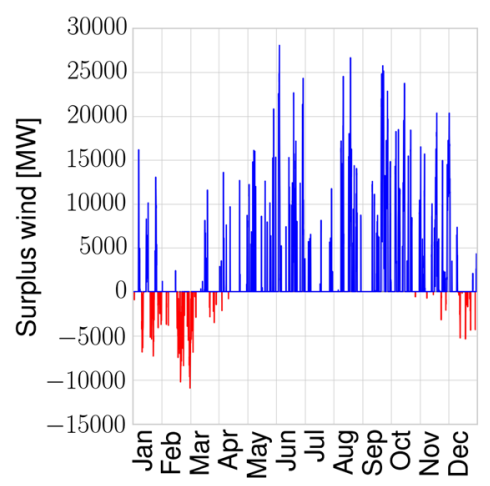

(b) Non-optimal: surplus $15 \mathrm{TWh}$, deficit $2 \mathrm{TWh}$, wind $161 \mathrm{TWh}$, hydro $135 \mathrm{TWh}$, demand 282 TWh.

Fig. 4 The details of surplus and deficit behavior in the proposed near-optimal (left) and a non-optimal scenario (right). While the total accumulated deficit in the non-optimal scenario remains low, the momentarily peaks are significant and call for a significant capacity of additional regulating power to meet the market demand

the cost of the wind-driven energy system. To put the $10 \mathrm{GW}$ into perspective, it is roughly one-third of the existing installed maximum hydropower capacity in Norway.

\section{Summary and outlook}

In light of the current study, the existing hydropower reservoirs of Norway could regulate up to $90 \mathrm{TWh}$ of wind-generated electricity before surplus generation becomes excessive 


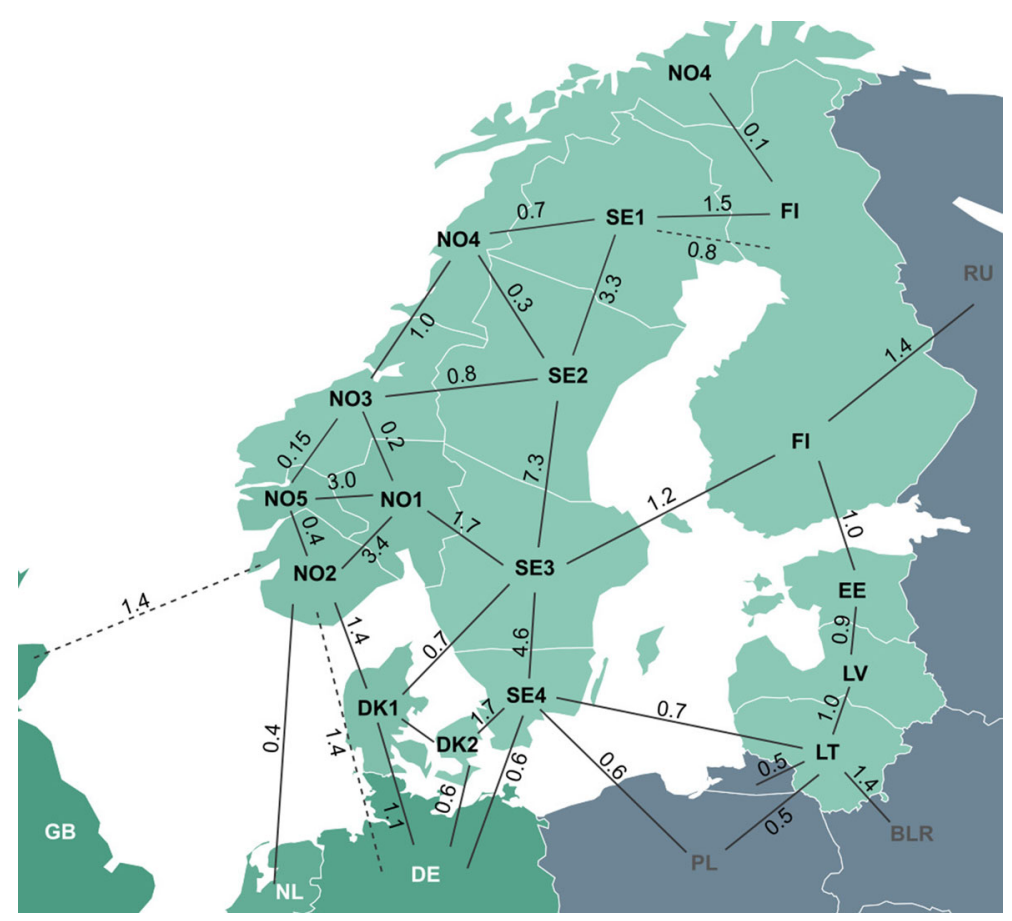

Fig. 5 Existing net transfer capacities (NTC) in gigawatts within the Nordpool region (solid lines). The larger of the NTCs between two regions has been chosen for display for better illustration of actual transfer capacities. The three dashed lines are confirmed plans between Norway and UK, Norway and Germany, and Sweden and Finland

affecting the utilization factor of the wind installments or significant momentarily deficits emerge that have to be met with other regulating electricity sources, typically with fossil sources. As the annual generation of electricity from wind during the year 2018 was 6 TWh in Finland, 16 TWh in Sweden, 15 TWh in Denmark and 4 TWh in Norway, accounting to a total of $41 \mathrm{TWh}$, the hydroreservoirs of Norway could support at least twice the existing wind capacity in the Nordic region and at least partially replace the remaining annual $44 \mathrm{TWh}$ of fossil-based electricity production in the Nordic market region that includes also Baltic countries. Naturally, it offers venues to regulate production also in Germany.

However, the governments and especially the grid operators in the market region should consider working in collaboration to design and invest into new grid infrastructure. This is not only desirable but mandatory if the full regulating potential of existing hydroreservoirs in the area is to be realized. The existing transfer capacities in the region are illustrated in Fig. 5 and, e.g., the transfer capacity to and from Norway-even after the two planned dashed lines to UK and Germany are completed-will be only $8 \mathrm{GW}$. Considering that our optimal scenario includes surplus days, the import-export capabilities to and from Norway should be near the level of typical daily consumption in Norway, i.e., around $17 \mathrm{GW}$. This would facilitate the country to draw in all of its daily electricity consumption during days there is excess wind in neighboring countries and, conversely, sell the saved hydroreserves during low-wind periods in neighboring countries. State-supported and -guaranteed, sufficient transferring capacities for large-scale wind integration in the whole of Nordpool region, if economically sensible, 
would encourage private investments and help meet the ambitious climate policies set for the next decades in the region.

In the near future, a more detailed study, involving the effects of localized production and consumption of the whole region, is planned for investigating the exact required transfer capacities between different market regions in the Nordpool area for optimal coupling of existing hydroreserves and hypothesized wind-energy production. Accurate modeling of the hydrosystem, including the effects of individual plants and reservoirs installed in parallel and series, should eliminate the possible overestimation of regulating resources of the one-entity model used in this study, specifically with respect to the maximum instantaneous power and reservoir status available.

Acknowledgements This research was funded through the Academy of Finland Grant No. 315278. Any subjective views or opinions expressed herein do not necessarily represent the views of the Academy of Finland or Aalto University.

Funding Open access funding provided by Aalto University.

Open Access This article is licensed under a Creative Commons Attribution 4.0 International License, which permits use, sharing, adaptation, distribution and reproduction in any medium or format, as long as you give appropriate credit to the original author(s) and the source, provide a link to the Creative Commons licence, and indicate if changes were made. The images or other third party material in this article are included in the article's Creative Commons licence, unless indicated otherwise in a credit line to the material. If material is not included in the article's Creative Commons licence and your intended use is not permitted by statutory regulation or exceeds the permitted use, you will need to obtain permission directly from the copyright holder. To view a copy of this licence, visit http://creativecommons.org/licenses/by/4.0/.

\section{Appendix A: Weekly Hydrological data source}

The following Python code snippet can be used to obtain the 20-year-average hydroreservoir data for Norway.

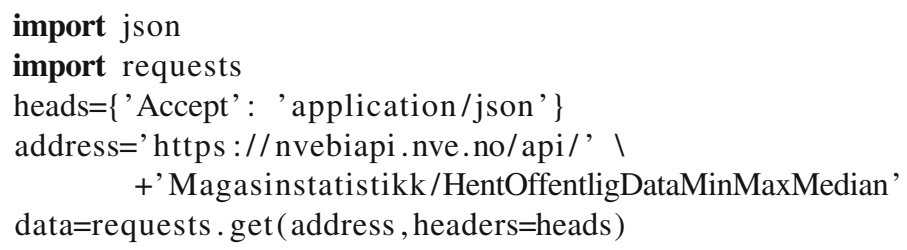

\section{Appendix B: Hourly windpower and demand data source}

After registering to Fingrid API system and receiving the personal key, the following Python code snippet can be used to obtain the data for hourly wind-electricity production and electricity demand in Finland.

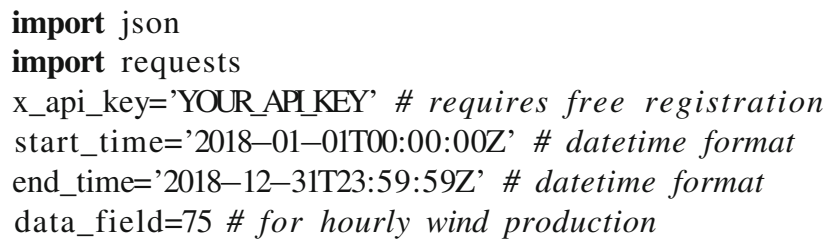




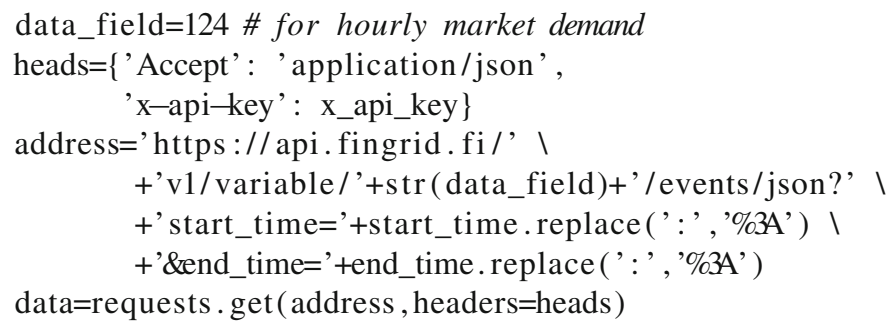

\section{References}

1. Y. Pan, R.A. Birdsey, J. Fang, R. Houghton, P.E. Kauppi, W.A. Kurz, O.L. Phillips, A. Shvidenko, S.L. Lewis, J.G. Canadell, P. Ciais, R.B. Jackson, S.W. Pacala, A.D. McGuire, S. Piao, A. Rautiainen, S. Sitch, D. Hayes, A large and persistent carbon sink in the World's forests. Science 333(6045), 988-993 (2011)

2. W. Yang, J. Yang, W. Guo, P. Norrlund, Response time for primary frequency control of hydroelectric generating unit. Int. J. Electr. Power Energy Syst. 74, 16-24 (2016)

3. Non-baseload Operation in Nuclear Power Plants: Load Following and Frequency Control Modes of Flexible Operation. Number NP-T-3.23 in Nuclear Energy Series. International Atomic Energy Agency, Vienna, (2018)

4. M.Z. Jacobson, M.A. Delucchi, Z.A.F. Bauer, S.C. Goodman, W.E. Chapman, M.A. Cameron, C. Bozonnat, L. Chobadi, H.A. Clonts, P. Enevoldsen, J.R. Erwin, S.N. Fobi, O.K. Goldstrom, E.M. Hennessy, J. Liu, J. Lo, C.B. Meyer, S.B. Morris, K.R. Moy, P.L. O’Neill, I. Petkov, S. Redfern, R. Schucker, M.A. Sontag, J. Wang, E. Weiner, A.S. Yachanin, 100\% clean and renewable wind, water, and sunlight all-sector energy roadmaps for 139 countries of the world. Joule 1(1), 108-121 (2017)

5. L. Calmfors, J. Hassler, N. Nasiritousi, K. Bäckstrand, F. Silbye, P.B. Sørensen, B. Carlén, B. Kriström, M. Greaker, R. Golombek, M. Hoel, K. Holtsmark, Nordic economic policy review 2019: Climate policies in the Nordics (2019)

6. F. Wagner, Considerations for an EU-wide use of renewable energies for electricity generation. Eur. Phys. J. Plus 129(10), 219 (2014)

7. H.-W. Sinn, Buffering volatility: a study on the limits of Germany's energy revolution. Eur. Econ. Rev. 99, 130 - 150 (2017). Combating Climate Change. Lessons from Macroeconomics, Political Economy and Public Finance

8. F. Wagner, E. Rachlew,. Study on a hypothetical replacement of nuclear electricity by wind power in Sweden. Eur. Phys. J. Plus 131, 16173-16178 (2016). QC 20180327

9. S. Pilpola, P.D. Lund, Different flexibility options for better system integration of wind power. Energy Strateg. Rev. 26, 100368 (2019) 